\title{
RESIDUAL STRESSES AND FATIGUE PERFORMANCE
}

\author{
M. N. James ${ }^{1}$, D. J. Hughes ${ }^{2}$, Z. Chen ${ }^{2}$, D. G. Hattingh ${ }^{3}$ and P. J. Webster ${ }^{4}$ \\ ${ }^{1}$ Faculty of Technology, University of Plymouth, Plymouth PL4 8AA, UK \\ ${ }^{2}$ FaME38, ILL-ESRF, Grenoble, Cedex 9, France \\ ${ }^{3}$ Department of Mechanical Engineering, PE Technikon, Port Elizabeth 6000, South Africa \\ ${ }^{4}$ Institute for Materials Research, University of Salford, Salford M5 4WT, UK
}

\begin{abstract}
Residual stresses are an inescapable consequence of manufacturing and fabrication processes, with magnitudes that are often a high proportion of the yield or proof strength. Despite this, their incorporation into life prediction is primarily handled through sweeping assumptions or conservative application of statistics. This can lead to highly conservative fatigue design methodologies or unforeseen failures under dynamic loading. The push from the desire for higher levels of materials performance, coupled with the pull of more sophisticated techniques for residual stress measurement, favours a reassessment of the accuracy of assumptions made about residual stresses and the modification during fatigue cycling. A viewpoint is also emerging that the fatigue performance of welded joints might be optimised through careful process control, coupled with understanding of the relative positions of, and interaction between, residual stress peaks, weld defects, hardness and microstructure. This paper will present information regarding the residual stress profiles in aluminium and steel welds obtained via synchrotron and neutron diffraction at the ESRF/ILL in Grenoble. Specimens were then subjected to specific cases of fatigue loading and the residual stress field was again measured. Difficulties associated with determining the strain-free lattice spacing will be mentioned, and the import of these data for life prediction modelling will be considered.
\end{abstract}

\section{INTRODUCTION}

Life prediction for components and structures is widely deemed to be a mature field, in the sense that the underlying fracture mechanics is well understood, as are the principles of a defect tolerant approach to fatigue lifing. Considerable insight has also been gained over the last 40 years into the perturbation of life prediction by microstructural, environmental and load influences. These major advances in capability allow us to design and build complex structures that operate with statistical reliability. Despite the sum of this knowledge, it remains challenging to incorporate precise effects associated with crack initiation, welded joints, manufacturing processes and fatigue crack closure. A large part of this uncertainty arises from the presence of residual stresses. These derive from manufacturing and joining processes, as well as from the crack growth process itself (crack tip plastic zone and crack wake effects). They therefore have variable magnitudes and are affected by the application of load cycles, particularly in the presence of stress concentrators such as weld toes, defects and cracks.

The presence of residual stresses is known to affect both initiation and growth of fatigue cracks, through changes to the effective mean stress experienced during fatigue cycling. Tensile residual stresses will add to applied stress levels and lead to fracture at lower loads than might be expected. In components like large castings, differential cooling rates in adjacent parts of the casting can lead to cracking under service loading, which may be self-arresting, but is always a cause of concern. Machining of large castings alters the self-equilibrating stress distribution and can lead to distortion problems. A related problem can be observed in welded joints, where there is a compromise to be made between joints made with high clamping restraint (and therefore higher residual stress levels) and those which have lower clamping restraint and are free to distort. 
Successful structural assemblies often require at least an implicit understanding of this balance, if not an explicit calculation of distortion and stresses.

Codified design of welded structures usually makes simplifying generic assumptions regarding residual stress levels. For instance, fatigue life prediction codes such as Eurocode 9 [1] or BS 7608 : 1993 [2] inherently rest on the idea that welded joints contain high (near-yield) levels of residual stress. This assumption underpins the assumed lack of sensitivity to mean stress effects during applied fatigue cycles, which has the advantage of making life prediction simpler. The disadvantage of such generalised assumptions, with the conjoint effect of required conservatism of fatigue design codes, is the application of 'lowest common denominator' design. In other words, no account is taken of any potential improvements in joint capability arising from alloy developments or weld process innovation. This is particularly detrimental in the case of a solid state process like friction stir welding (FSW), which delivers joints with good grain structure, low defect population and low geometric stress concentration. Evidence indicates that FSW joints have high fatigue performance and low values of tensile residual stress [3, 4].

The other side of the residual stress conundrum relates to the use of compressive residual stresses to enhance fatigue life, e.g. in shot peening. Shot peening parameters are still chosen empirically via Almen strip deflection, and little reliable information is available in the literature concerning values of residual stress as a function of alloy and shot peening conditions (coverage, peening intensity, angle, type of shot). There is considerable current interest in developing advanced fatigue life prediction models that incorporate residual stress values [5, 6]. Controversy exists in the shot peening and fatigue community as to whether the major benefits of shot peening should be ascribed to the compressive residual stresses or to microstructural changes which occur over the same region.

This controversy adversely affects our ability to predict the fatigue life of peened components, and arises partly because of uncertainties in accurately measuring the magnitude of residual stresses through the depth of the shot peened layer, and partly from lack of knowledge of the effect of fatigue cycling on such stresses. Some work has reported that shot peening stresses relax rapidly during fatigue cycling [7, 8], whilst work on residual stresses in FSW butt welds in a work hardening aluminium alloy has indicated that their magnitude may increase during fatigue cycling [1].

This is an important issues in life prediction for shot peened components. Recent work [6] dealing with the optimisation of the shot peening process presented a microstructural fracture mechanics model that offers the potential to make realistic life predictions for shot peened components, taking account of all relevant factors, e.g. hardness, grain size, plastic deformation, small crack growth mechanics and residual stress magnitude. The potential improvement offered by this technique could not be properly assessed against experimental data because of poor knowledge of the residual stress field. The stresses must be measured over a depth of at least several millimetres below the surface, as this region has a major influence on fatigue life for small cracks. This means that laboratory x-ray diffraction data is not useful, while incremental hole drilling is unreliable and semi-destructive, and hence shifts crack initiation to the hole under subsequent fatigue cycling. Numerical models of shot peened components have been attempted but show poor correspondence between their results and those obtained from x-ray and hole drilling data [9]. The authors (with colleagues for Sheffield University - J. R. Yates and D. Asquith) recently performed a systematic synchrotron diffraction investigation of residual stresses in shot peened 7050-T7451 alloy using specimens made with several machining sequences and two shot peening coverage values. Strains were measured before and after fatigue cycling (experiment ME 748 at the ESRF).

Much of the difficulty with residual stress measurements arises from limitations associated with surface measurements, imprecision in hole drilling parameters and relatively small data sets. 
Modern high intensity synchrotron and neutron radiation sources, however, coupled with improved data analysis software and automated stages, allow large sets of strain data to be acquired from relatively thick plates of steel or aluminium. Thus the remit of this paper is to demonstrate the opportunities offered by neutron and synchrotron diffraction strain scanning to provide sufficiently detailed data to assist in resolving some outstanding problems associated with residual stresses.

\section{WELDED JOINTS IN ALUMINIUM ALLOYS}

The work reported in this paper covers the as-welded residual stress state and the effect of fatigue cycling on friction stir (FS) and metal inert gas (MIG) butt welds made in $8 \mathrm{~mm}$ plate of 5083H321 aluminium alloy. This is a marine grade strain-hardening structural alloy. The scientific aim of the work was to use the residual stress data to gain insight into two different aspects of the influence of process type and conditions on fatigue performance.

Firstly, there was interest in whether the use of crack growth rate data for small fatigue cracks would allow prediction of the variability observed in S-N curves for butt welds made under different conditions with different process types. To address this question requires several steps:

1. The generation of small crack growth rate curves using surface replication of small hourglass fatigue specimens, machined such that crack initiation occurred in the same weld region as observed in larger as-welded specimens.

2. Correlation of small crack growth rate relationships for the various specimen conditions using an expression based on crack tip opening displacement and yield strength. This has previously proved useful in obtaining a single curve that defined crack growth rate behaviour for a range of microstructures in an aluminium casting alloy [10].

3. The incorporation of the effects of weld stress concentrations and residual stresses into a fracture mechanics life integration to predict the observed S-N curves for as-welded fatigue specimens.

Secondly, a novel technique has been developed by the authors that allows on-line monitoring of a polar plot of tool forces during FS welding [11]. This gives a twin-lobed 'force footprint' that is related to the energy input into a friction stir weld and potentially provides fundamental information about the mechanisms underlying weld nugget formation. One can then systematically examine the relationships among fatigue performance, energy input into the weld and weld process parameters such as tool rotational speed, tool feed rate along the weld and tool geometry. Figure 1 shows typical force footprint data for a series of FS welds made in $6 \mathrm{~mm}$ 5083-H321 aluminium alloy plate with different pitch values (defined as tool advance per revolution).

\section{RESIDUAL STRESSES IN BUTT WELDS}

Full details of the synchrotron diffraction strain scanning are given in reference 4, and because of the necessary brevity of this paper, only a few essential details will be repeated here. The work was performed on the crystal diffraction beamline BM16 at the European Synchrotron Radiation Facility in Grenoble. Reflections from the $\left.\begin{array}{llll}3 & 1 & 1\end{array}\right\}$ planes were used, giving detector angles of approximately $2 \theta=14.5^{\circ}$ which, with receiving slit dimensions of $0.3 \times 1.0 \mathrm{~mm}$, gave elongated diamond shaped gauge volumes with an aspect ratio of about 8:1. Specimens were $150 \mathrm{~mm}$ along the weld line and $190 \mathrm{~mm}$ transverse to it. This is large enough to preserve the full residual stress field associated with the weld. Measurements were made of the stresses parallel to, and transverse to, the weld for friction stir and MIG welds. Both single pass (SP) welds and double pass (DP) Fs welds were consdiered. These measurements were made on the central plane transverse to the weld line and a typical map of strain of stress comprised around 1080 data points. 


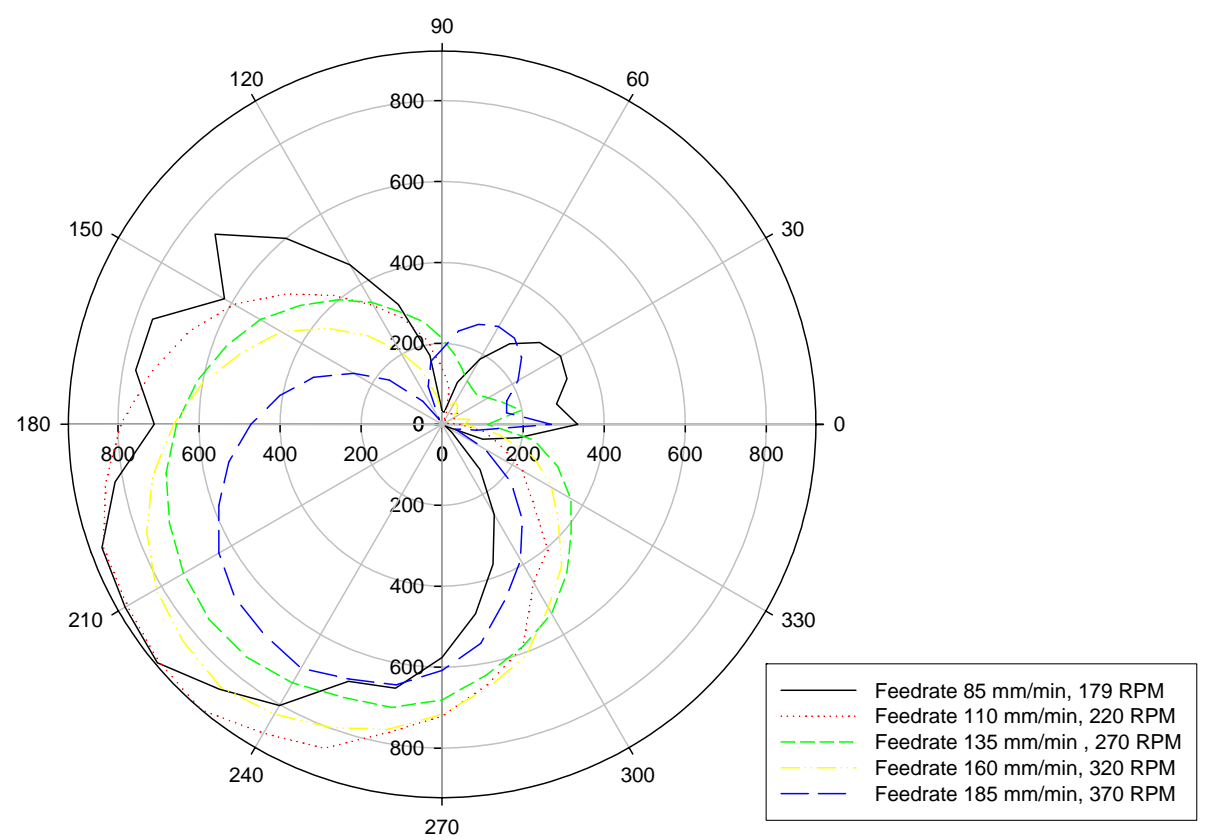

Figure 1: Double-lobed polar plot contours for constant FSW weld pitch of $0.5 \mathrm{~mm}$.

Figure 2 shows maps of transverse stress for the SP and DP FS welds. Line data can be extracted from these maps to enhance the interpretation of trends. These measurements were repeated at selected z-positions in certain plates after bend fatigue cycling. Peak stresses in the fatigue loading were chosen to correspond to lives of around $10^{5}$ cycles and $10^{7}$ cycles.

a) DP FSW Transverse Stress (MPa)

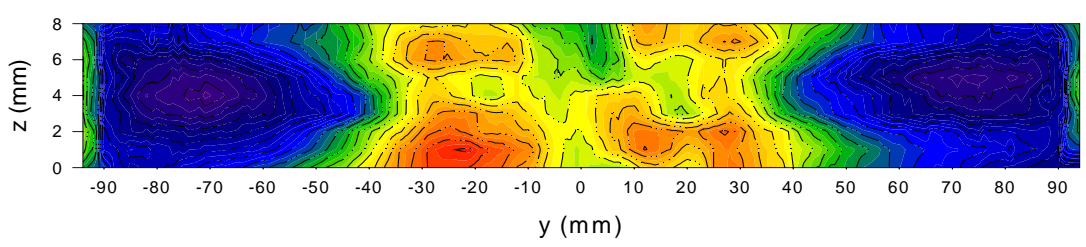

b) SP FSW Transverse Stress (MPa)

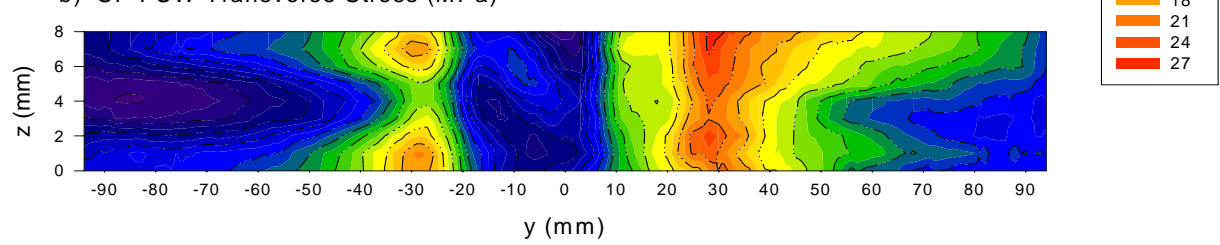

Figure 2: Contour maps of transverse stress on centre plane for SP and DP welds. 
Typical line data obtained for 2-pass MIG welds made with a heat input of $0.56 \mathrm{~kJ} / \mathrm{mm}$ and a travel speed of $600 \mathrm{~mm} / \mathrm{min}$ are shown below in Figure 3. For the welds shown bend fatigue loading was applied with peak stresses of $100 \mathrm{MPa}$ to $200 \mathrm{MPa}$, and Figure 3 compares the aswelded stresses with those observed after 100 cycles of fatigue loading. Stresses transverse to (Y direction) and parallel with (X direction) the weld line are shown.

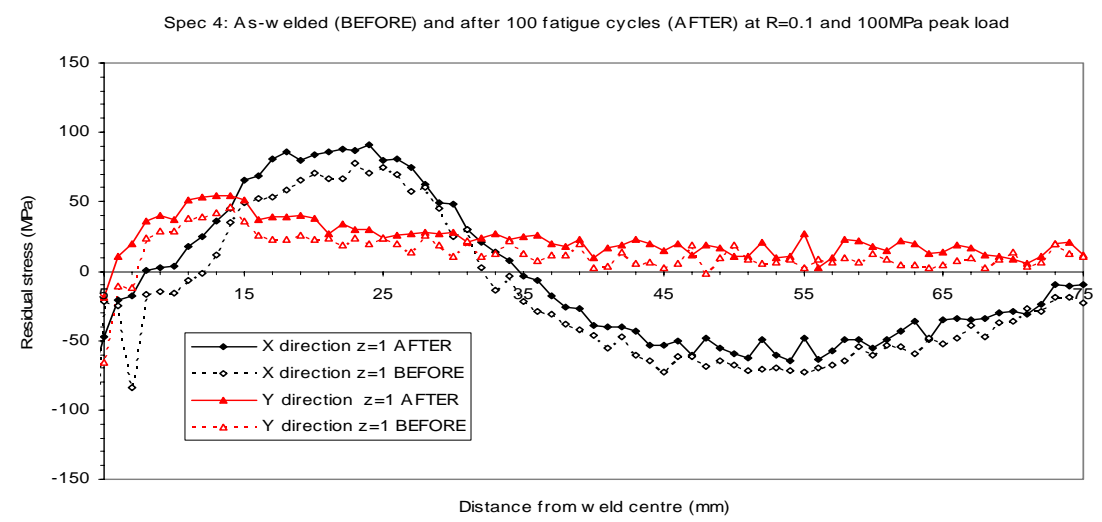

Spec 5: As-w elded (BEFORE) and after 100 fatigue cycles (AFTER) at R=0.1 and 200MPa peak load

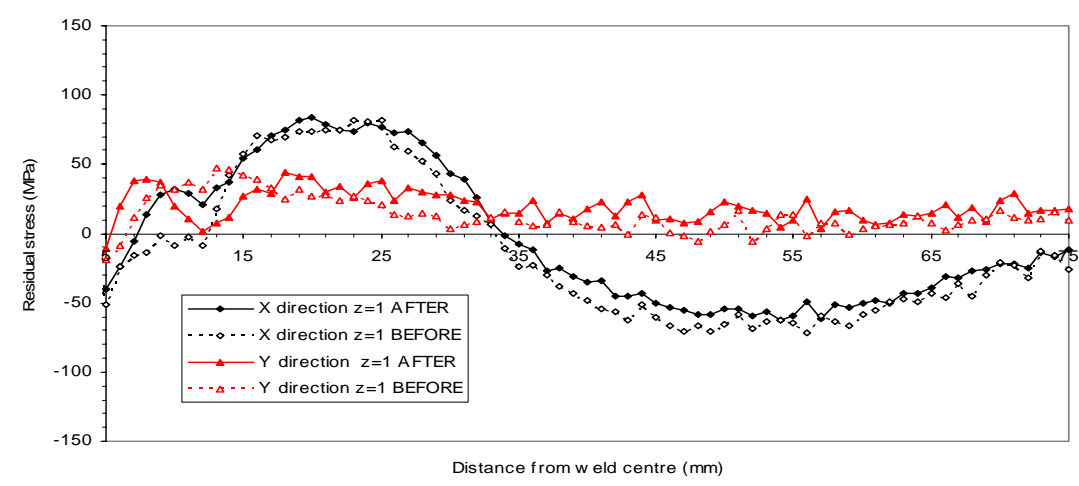

Figure 3: Residual stresses in MIG welds subject to two different fatigue loads.

Space precludes detailed discussion of neutron diffraction data for the residual strain in butt welds made in $12 \mathrm{~mm}$ plate of high performance structural steel (794 MPa yield strength). However, fast measurement times of 10-15 seconds can be obtained, and Figure 4 shows a map of transverse strain comprising some 2000 data points. These data were obtained as part of a systematic investigation of the role of weld process conditions (filler metal yield strength and heat input) in varying the slope and peak magnitudes of residual strains at the critical positions for fatigue crack initiation, i.e. the weld toe.

Determination of the strain-free lattice spacing in textured and welded alloys can be difficult and readers are referred to reference 4 for a detailed discussion. 


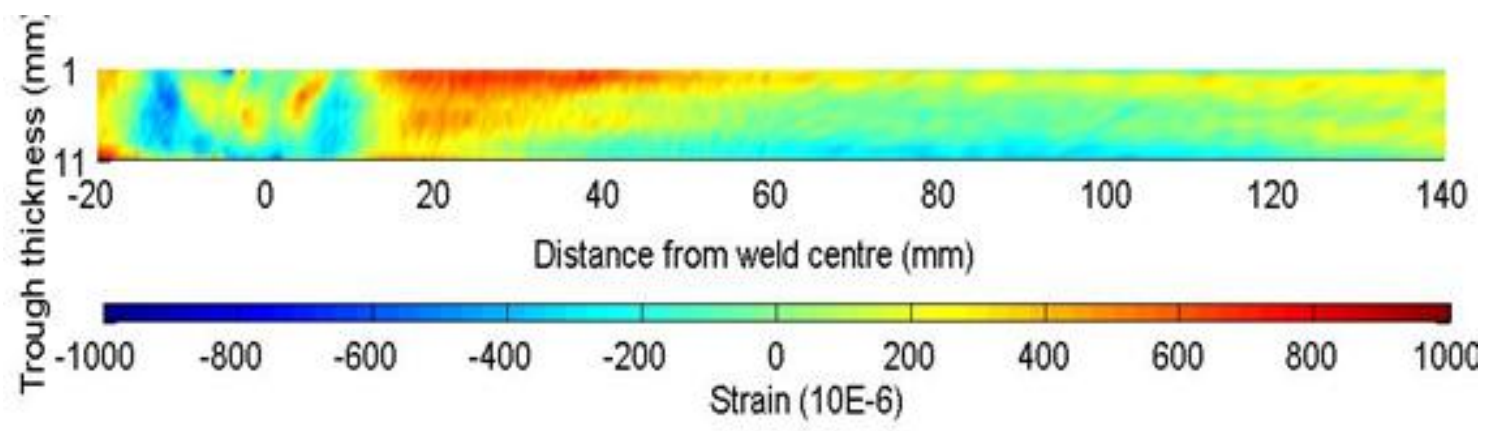

Figure 4: Map of transverse strain in a steel weld obtained by neutron diffraction.

\section{REFERENCES}

1. Eurocode 9: Design of aluminium structures - Part 2: Structures susceptible to fatigue, ENV 1999-2:1998, European Committee for Standardisation.

2. BS 7608 : 1993, Code of Practice for Fatigue design and assessment of steel structures, British Standards Institution.

3. Webster, P.J., Oosterkamp, L.D., Browne, P.A., Hughes, D.J., Kang, K.P., Withers, P.J. and Vaughan, G.B.M. (2001), Synchrotron X-ray residual strain scanning of a friction stir weld, Journal of Strain Analysis for Engineering Design, Vol. 36 No. 1 pp.61-70.

4. James, M.N., Hughes, D.J., Hattingh, D.G., Bradley, G.R., Mills, G. and Webster, P.J. (2004), Synchrotron Measurement of Residual Stresses in Friction Stir Welded 5383-H321 Aluminium Butt Joints and Their Modification by Fatigue Cycling, Fatigue and Fracture of Engineering Materials and Structures, Vol. 27, pp.187-202.

5. Guagliano, M. and Vargani, L. (2004) An approach for prediction of fatigue strength of shot peened components, Engineering Fracture Mechanics, Vol. 71, pp.501-512.

6. Romero, J.S. (2002), Optimisation of the shot peening process in terms of fatigue resistance, PhD Thesis, University of Sheffield.

7. Schütz, W. (1981), Fatigue life improvement of high strength materials by shot peening, Proceedings of the $1^{\text {st }}$ International Conference on Shot Peening (ICSP-1), Paris, Editor: A Niku-Lari, Pergamon Press, pp.423-433.

8. Zhuang, W.Z. and Halford, G.R. (2001), Investigation of residual stress relaxation under cyclic load, International Journal of Fatigue, Vol. 23, Supplement 1, 2001, pp.31-37.

9. Smith, D.J., Farrahi, G.H., Zhu, W.X. and McMahon, C.A. (2001), Experimental measurement and finite element simulation of the interaction between residual stresses and mechanical loading, International Journal of Fatigue Vol. 23 pp.293-302.

10. Caton, M.J., Jones, J.W., Boileau, J.M. and Allison, J.E. (1999), The effect of solidification rate on the growth of small fatigue cracks in a cast 319-type aluminium alloy, Metallurgical and Materials Transactions, Vol. 30A No. 12, pp.3055-3068.

11. Hattingh, D.G., van Niekerk, T.I., Blignault, C., Kruger, G. and James, M.N. (2004), Analysis of the FSW force footprint and its relationship with process parameters to optimise weld performance and tool design, in press, Welding in the World. 